\title{
ANALISIS PENINGKATAN KUALITAS PERMUKIMAN KUMUH DI DESA LOH SUMBER KABUPATEN KUTAI KARTANEGARA
}

\author{
Lisa Astria Milasari ${ }^{1)}$, Faizal Baharuddin"1), Rusdi Doviyanto ${ }^{1)}$ \\ 1) Program Studi Arsitektur, Fakultas Teknik, Universitas 17 Agustus 1945 Samarinda, Kaltim
}

\begin{abstract}
Population growth is a high primary need, one of which is the need for housing. The existence of slum settlements in the Kutai Kartanegara Regency has an indication of social and environmental problems. From the results of the location justification that the densest slum area is in Loh Sumber Village in RT. 02 and RT. 03 with a land area of 5.31 hectares. This study aims to provide input through the concept of improving the quality of slum settlements, with the research approach used is a rationalistic approach, based on truth. The research method is in the form of a qualitative descriptive study, with the answer to an ongoing problem. The research indicators and variables are (1) the physical condition of the building, with the variables of building density and building quality; and (2) The condition of facilities and infrastructure, with variables of road environmental quality, environmental drainage, quality of drinking water network, solid waste management, quality of wastewater and sanitation, and public street lighting. The results of the discussion are the concept of rejuvenation in the form of the use of building roof materials, and the use of wood types as building materials with strong resistance to air, repair of environmental roads with concrete and paving blocks, by changing the direction of the directions. as a street name marker, improve the quality and quantity of the system. clean water, manufacture of wastewater from IPAL / IPLT, determine the location of TPS, and public street lighting. The need for local government cooperation in implementing community needs and involving the active role of the community in maintaining a clean and safe residential environment.
\end{abstract}

Key Words: indicator, quality improvement, slum area.

\section{PENDAHULUAN}

Perkembangan kota merupakan fungsi waktu, merupakan proses perubahan keadaan dari satu waktu ke waktu yang lain. (Yunus, 2000). Meningkatnya pertumbuhan penduduk serta aktivitasnya berdampak pada kebutuhan lahan untuk permukiman. Penyelenggaraan perumahan dan kawasan permukiman meliputi kegiatan perencanaan, pembangunan, pemanfaatan dan pengendalian termasuk di dalamnya pengembangan kelembagaan pendanaan dan sistem pembiayaan, serta masyarakat terkoordinasi dan terpadu (UU No 1 Tahun 2011 tentang Perumahan dan Kawasan Permukiman). Permukiman dapat diartikan sebagai suatu tempat atau lingkungan dimana manusia tinggal, berkembang serta melangsungkan hidupnya. (Budiharjo, 2009). Pada hakikatnya, permukiman merupakan lingkungan dimana masyarakat mempengaruhi dan memanfaatkan lingkungan tersebut. Permukiman memiliki dua arti yang berbeda, yaitu isi yang menunjuk pada manusia sebagai penghuni maupun masyarakat lingkungan sekitar, dan wadah yang menunjuk pada fisik hunian terdiri dari alam dan elemen-elemen buatan manusia. (Sastra \& Marlina, 2006).

Kurangnya perencanaan dan peningkatan kualitas permukiman, menyebabkan batasan ruang huni yang ditempati masyarakat kurang memadai, kurang nyaman dan berdampak negatif pada lingkungan permukimannya. Salah satunya pada permukiman kumuh yang merupakan masalah dihadapi oleh kota-kota besar di Indonesia, pada umumnya mencakup kondisi fisik, kondisi sosial ekonomi dan kondisi budaya bermukim. Permukiman kumuh sering dilihat sebagai suatu kawasan yang identik dengan kawasan yang apatis, kelebihan penduduk, tidak mencukupi, tidak memadai, miskin, bobrok, berbahaya, tidak aman, kotor, dibawah standar, tidak sehat dan masih banyak stigma negatif lainnya (Adisasmita, 2005). Fenomena pertumbuhan penduduk yang tinggi berdampak pada banyaknya persoalan yang disebabkan oleh urbanisasi.

Keberadaan kawasan permukiman kumuh diakibatkan adanya daya tarik daerah perkotaan dengan tingkat pelayanan fasilitas yang tinggi dan kemudahan jangkauan, dapat menimbulkan 
aglomerasi kantong-kantong miskin pada kawasan permukiman yang kumuh, padat bahkan illegal. Di sisi lain, terkait tatanan sosial budaya kemasyarakatan di lingkungan permukiman kumuh, yang pada umumnya termasuk golongan masyarakat berpenghasilan rendah, penggunaan fungsi ruang mengalami perubahan signifikan terkait penghasilan.

Berbagai upaya dilakukan untuk penanganan kualitas permukiman, seperti: air bersih, sanitasi, drainase dan indikator terkait. Berdasarkan data Rencana Pencegahan dan Peningkatan Kualitas Permukiman Kumuh Perkotaan (RP2KPKP) Kabupaten Kutai Kartanegara Tahun 2016, permukiman kumuh di Kabupaten Kutai Kartanegara disebabkan oleh ketidaklengkapan atau kurangnya akses terhadap layanan perasarana, sarana dan utilitas penunjang perumahan dan permukiman, kepadatan bangunan tinggi, ketidakteraturan bangunan, serta tidak sesuai dengan alokasi peruntukan Perumahan dan Kawasan Permukiman (PKP) dalam Rencana Tata Ruang Wilayah (RTRW).

Pemerintah Daerah dapat memberikan masukan dalam penetapan kawasan perumahan kumuh (Peraturan Bupati Kutai Kartanegara No 119 Tahun 2016 tentang Pencegahan dan Peningkatan Kualitas Perumahan Kumuh dan Permukiman Kumuh), dan permukiman kumuh dengan luasan diatas $10 \mathrm{Ha}$ sampai dengan $15 \mathrm{Ha}$ yang menjadi kewenangan Pemerintah Provinsi Kalimantan Timur.

Berdasarkan kondisi fisik, Desa Loa Kulu Kota, Desa Loh Sumber, dan Desa Jembayan memiliki karakteristik bangunan padat dengan jenis bangunan semi permanen dan mayoritas bahan bangunan berasal dari kayu, dengan KDB rata-rata mencapai $80 \%$. Kondisi jaringan jalan terbagi atas 2 jenis jaringan akses, yaitu: jalan cor serta kondisi perkerasan rusak ringan dan jalan kayu. Kondisi sanitasi lingkungan pada kawasan kumuh masih kurang baik dan masih dibawah standar pelayananan masyarakat (SPM). Sistem persampahan di kawasan permukiman kumuh masih belum terlayani karena tidak adanya lokasi tempat penampungan sampah sementara, sehingga masih mengandalkan metode pembakaran sampah.

Berdasarkan perkembangannya, permukiman kumuh di Desa Loa Kulu Kota, Desa Loh Sumber, dan Desa Jembayan memiliki karakteristik yang sama dengan permukiman lainnya. Akan tetapi, penelitian ini memfokuskan pada satu desa sebagai obyek penelitian, yakni Desa Loh Sumber dengan lokasi di RT. 02 dan RT. 03, dimana sebagian bangunan rumah merupakan rumah terapung di tepian sungai. Dengan bentuk dasar permukiman berbentuk pita berdimensi memanjang jauh lebih besar dari melebarnya, sehingga hambatan perluasan ke area menyamping menjadi lebih besar. (Milasari, 2020)

Strategi penataan ruang wilayah Kabupaten Kutai Kartanegara terkait dengan peningkatan kualitas kawasan kumuh perkotaan. Selain itu, keberadaan permukiman kumuh di Kabupaten Kutai Kartanegara mengindikasikan munculnya permasalahan sosial dan lingkungan.

Berangkat dari masalah tersebut, tujuan penelitian ini adalah memberikan masukan melalui konsep peningkatan kualitas permukiman kumuh dalam bentuk rencana sarana prasarana serta pendekatan perbaikan fisik dan lingkungan kawasan, sehingga dapat diterapkan sesuai dengan karakteristik permukiman kumuh di Desa Loh Sumber, Kabupaten Kutai Kartanegara.

\section{METODOLOGI}

Pendekatan penelitian yang digunakan adalah pendekatan rasionalistik, yaitu pendekatan yang berdasarkan pada kebenaran. Metode penelitian ini merupakan penelitian terapan dengan jenis penelitian deskriptif kualitatif. Data penelitian kualitatif deskriptif adalah data yang dikumpulkan lebih mengambil bentuk kata-kata atau gambar daripada angka-angka (Emzir, 2012). Analisis kualitatif digunakan karena penelitian ini tidak bersifat menguji hipotesis dari suatu teori melainkan mengekplorasi suatu permasalahan yang sedang terjadi dengan memanfaatkan teori-teori yang telah ada.

Metode pengumpulan data menggunakan survey primer dan survey sekunder. Untuk survey primer berdasarkan observasi lapangan dan kuisioner pada lokasi penelitian, sedangkan pada survey sekunder didapat dari data dari instansi terkait.

Penentuan indikator dan variabel penelitian ini (Tabel 1) didasarkan pada sintesa teori dalam menjawab sasaran pada penelitian, yaitu: identifikasi karakteristik permukiman kumuh, analisis faktor prioritas penyebab kawasan permukiman kumuh dan peningkatan kualitas kawasan permukiman kumuh perkotaan di Desa Loh Sumber, Kecamatan Loa Kulu, Kabupaten Kutai Kartanegara.

\section{Populasi dan Responden}

Segmen responden penelitian ini berasal dari pihak stakeholder, untuk mengetahui prioritas dari bobot setiap faktor yang berpengaruh dalam pengembangan kawasan permukiman. Populasi dalam penelitian ini berada di Desa Loh Sumber di RT. 02 dan RT. 03, dengan jumlah rumah 643 unit, dengan jumlah sampel yang dihitung, adalah:

$$
n=N /\left(1+N \cdot e^{2}\right)
$$


Cantilever | Volume: 10 Nomor: 01 April 2021 ISSN: 1907-4247 (Print) $\mid$ ISSN: 2477-4863 (Online) | Website: http://cantilever.id Lisa Astria Milasari, dkk. | Analisis Peningkatan Kualitas Permukiman Kumuh di Desa Loh Sumber Kabupaten Kutai Kartanegara

$$
\begin{aligned}
\text { dimana } & \text { : } \\
\mathrm{n} & =\text { jumlah responden } \\
\mathrm{N} & =\text { jumlah populasi } \\
\mathrm{e} & =\text { besar toleransi yang digunakan }(10 \%) \\
\mathrm{n} & =643 /\left(1+\left(643 \times 0,1^{2}\right)\right) \\
& =643 /(1+6,43 \\
& =643 / 7,43 \\
& =86,54 \text { dibulatkan } 87 \text { sampel responden }
\end{aligned}
$$

Tabel 1. Indikator dan Variabel Penelitian

\begin{tabular}{clll}
\hline No & Indikator & Variabel & Definisi operasional \\
\hline 1 & Kondisi & Tingkat & Jumlah bangunan \\
& Fisik & kepadatan & rumah \\
& Bangunan & Kualitas & Kondisi dan jenis \\
& & bangunan & material bangunan \\
2 & Kondisi & Kualitas & Jenis jaringan jalan \\
& sarana dan & jaringan jalan & \\
& prasarana & Kualitas & Kondisi dan \\
& & jaringan air & ketersediaan jaringan \\
& & minum & air minum/bersih \\
& & Pengelolaan & Kondisi dan \\
& & persampahan & ketersediaan fasilitas \\
& & persampahan \\
& & Kualitas air & Kondisi dan \\
& & ketersediaan air limbah \\
& & Kualitas & Kondisi dan \\
& & prasarana & ketersediaan prasarana \\
& & sanitasi & sanitasi \\
& & Penerangan & Kondisi dan \\
& & jalan umum & ketersediaan PJU \\
\hline & &
\end{tabular}

\section{HASIL DAN PEMBAHASAN}

Kabupaten Kutai Kartanegara merupakan salah satu kabupaten di Provinsi Kalimantan Timur, dengan ibukota Kota Tenggarong. Kabupaten Kutai Kartanegara memiliki luas wilayah $27.263,10 \mathrm{~km}^{2}$ dan luas perairan kurang lebih $4.097 \mathrm{~km}^{2}$. Dengan adanya perkembangan dan pemekaran wilayah, Kabupaten Kutai Kartanegara terbagi dalam 18 wilayah kecamatan dan 237 desa/ kelurahan.

Lokasi permukiman kumuh terdapat di Kawasan Loa Kulu yang berada di Desa Loa Kulu Kota, Desa Loh Sumber dan Desa Jembayan dengan luasan lahan 11,56 Ha (Peraturan Bupati Kutai Kartanegara Nomor 376/SK-BUP/HK/2016 tentang Penetapan Lokasi Kawasan Permukiman Kumuh). Dari hasil survey, justifikasi, identifikasi, dan analisa, kawasan permukiman kumuh terpadat berada di Desa Loh Sumber di RT. 02 dan RT. 03 dengan luas lahan 5,31 hektar.

Desa Loh Sumber merupakan salah satu desa di Kecamatan Loa Kulu Kota, Kabupaten Kutai Kartanegara dengan Pusat Pelayanan Lingkungan yang berfungsi untuk melayani kegiatan skala kecamatan atau beberapa desa di suatu kecamatan. Desa Loh Sumber memiliki karakteristik padat permukiman dan jumlah penduduk 1.438 jiwa dengan jumlah rumah tangga (RT) sebanyak 10 RT. Adapun permasalahan yang tampak, adalah: saluran

\begin{tabular}{|c|c|}
\hline Kriteria & Permasalahan \\
\hline $\begin{array}{l}\text { Bangunan } \\
\text { gedung }\end{array}$ & $\begin{array}{l}\text { - Jumlah bangunan } 248 \text { unit. } \\
\text { - Jenis bangunan terdiri dari non permanen, } \\
\text { semi permanen dan permanen. } \\
\text { - Kondisi atap terdiri atas bocor dan tidak } \\
\text { bocor. } \\
\text { - Kondisi dinding bangunan baik dan rusak. } \\
\text { - Jenis lantai bangunan tanah dan bukan } \\
\text { tanah/semen/tehel. }\end{array}$ \\
\hline $\begin{array}{l}\text { Jalan dan } \\
\text { drainase } \\
\text { lingkungan }\end{array}$ & $\begin{array}{l}\text { - Total panjang jalan lingkungan } 1.845,5 \\
\text { meter. } \\
\text { - } 140 \text { meter kualitas jalan lingkungan buruk. } \\
\text { - Total panjang drainase } 474 \text { meter. } \\
\text { - } 51 \text { meter saluran drainase tidak } \\
\text { terpelihara. } \\
\text { - } 120 \text { meter tidak tersedia saluran drainase. }\end{array}$ \\
\hline $\begin{array}{l}\text { Penyediaan } \\
\text { air minum }\end{array}$ & $\begin{array}{l}643 \mathrm{KK} \text { telah terlayani kebutuhan air } \\
\text { minum. }\end{array}$ \\
\hline $\begin{array}{l}\text { Pengelolaan } \\
\text { air limbah }\end{array}$ & $\begin{array}{l}\text { Belum terbangunnya fasilitas pengelolaan } \\
\text { limbah (IPLT dan IPAL) untuk melayani } \\
\text { pembuangan air limbah dari penduduk. }\end{array}$ \\
\hline $\begin{array}{l}\text { Pengelolaan } \\
\text { persampahan }\end{array}$ & $\begin{array}{l}\text { Sampah rumah tangga masih dibakar, } \\
\text { dibuang di ruang terbuka/ lahan kosong, } \\
\text { dan di sungai/drainase. }\end{array}$ \\
\hline $\begin{array}{l}\text { Penerangan } \\
\text { jalan umum }\end{array}$ & Tidak ada penerangan jalan umum. \\
\hline
\end{tabular}
drainase yang tidak terpelihara dan tidak memenuhi persyaratan teknis, dan belum adanya pengelolaan persampahan. Permasalahan di Desa Loh Sumber tersaji dalam Tabel 2, sedangkan hasil delineasi permukiman kumuh di Desa Loh Sumber terlihat dalam Gambar 1.

Tabel 2. Indikator Permasalahan

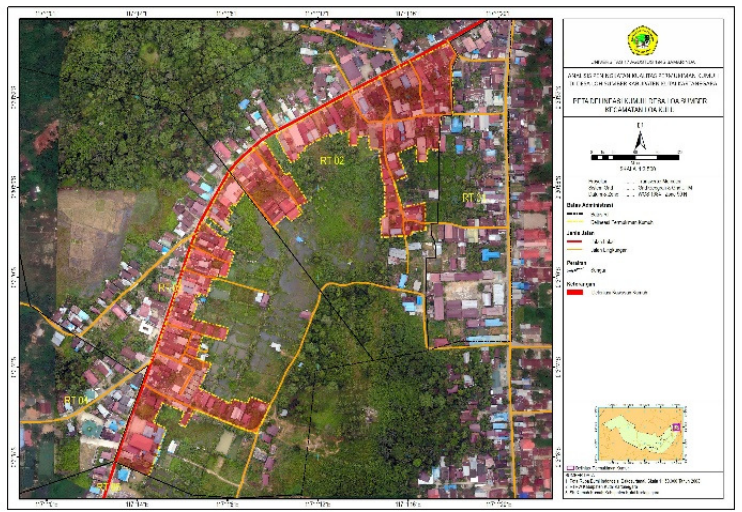

Gambar 1. Delienasi permukiman kumuh RT. 02 \& RT. 03

\section{Analisis Bangunan}

Berdasarkan hasil survey lapangan, rumahrumah tergolong dalam rumah semi dan non permanen. Rumah-rumah tersebut mengelompok dalam satu satuan permukiman dengan tata letak yang tidak beraturan, dan memiliki kerapatan satu sama lain yang menunjukkan tingkat kepadatan tinggi, dengan kepadatan bangunan 0,10 unit bangunan $/ \mathrm{m}^{2}$, dimana menurut Ditjen Bangda Kemendagri, kawasan kumuh memiliki kepadatan bangunan $>110$ bangunan/ha (Nursyahbani \& 
Pigawati, 2015). Sedangkan bentuk fisik (kualitas bangunan), berupa: $30,2 \%$ bangunan permanen sebesar, 6,09\% semi permanen, dan $62,9 \%$ non permanen.

\section{Analisis Sarana Prasarana}

Cakupan pelayanan jalan lingkungan dapat dilihat dari dua indicator, yaitu: perlunya keterhubungan antar permukiman dalam lingkup permukiman skala wilayah, dan perlunya keterhubungan antar persil dalam perumahan dalam skala kawasan. Titik lokasi pada Desa Loh Sumber, diantaranya:

1. Jl. Mulyo Pranoto Gang Dahlia, RT. 02.

2. Jl. Mulyo Pranoto Gang Kenanga, RT. 02.

3. Jl. Mulyo Pranoto, Gang Murai RT. 03.

4. Jl. Mulyo Pranoto Gang Nusa Indah RT. 02.

5. Jl. Mulyo Pranoto Gang Melati, RT. 02.

6. Jl. Mulyo Pranoto, Gang Anggrek, RT. 02.

7. Jl. Mulyo Pranoto Gang Gunung Timur, RT. 03.

RT. 02 dan RT. 03 Desa Loh Sumber memiliki jalan lingkungan tidak memadai sebesar 35\%.
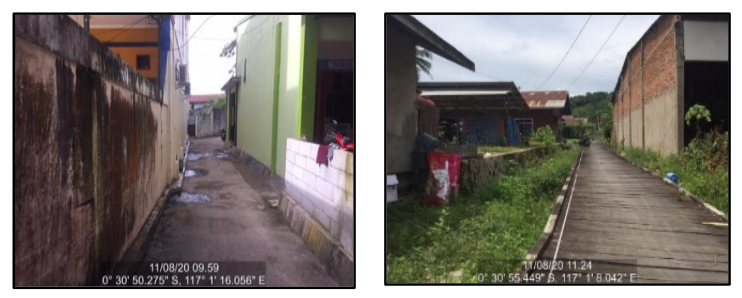

Gambar 2. Salah satu kondisi jalan lingkungan RT. 02 \& 03

Secara garis besar, terdapat permasalahan drainase lingkungan di lapangan, yaitu: saluran drainase yang tidak terpelihara, tumpukan sedimentasi dari pondasi rumah warga, dan tumpukan sampah.
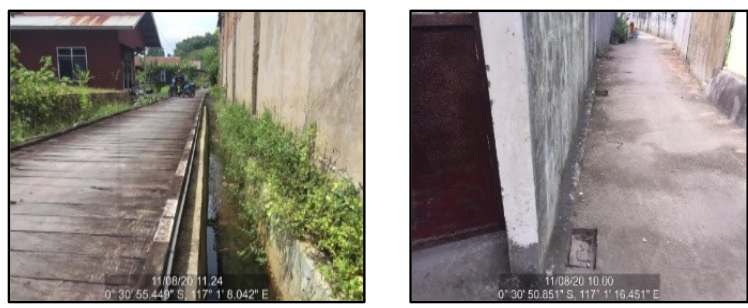

Gambar 3. Salah satu kondisi drainase lingkungan

Pada wilayah permukiman kumuh di Desa Loh Sumber, saat ini belum tersedia IPAL maupun IPLT. Sebagian besar rumah tangga di Desa tersebut memiliki jamban sendiri (= 57,92\%), jamban bersama $(=23,3 \%)$, jamban umum $(=6,23 \%)$, tidak memiliki jamban $(=12,47 \%)$.

Kebutuhan air minum di kawasan ini sudah terlayani oleh jaringan PDAM, tetapi belum mengalir selama 24 jam. Sehingga, perlu adanya peningkatan pelayanan baik dari segi kapasitas debit maupun perluasan jaringan air minum.

Wilayah Kecamatan Loa Kulu Kota masih belum memiliki sarana dan prasarana persampahan. Akibatnya, banyak sampah yang dibakar dan dibuang sembarang, terutama di pinggir jalan dan pinggiran sungai, sehingga berpotensi mencemari lingkungan.

Lampu penerangan jalan dipasang di kiri atau kanan, atau di median jalan. Lampu penerangan jalan digunakan untuk menerangi jalan maupun lingkungan di sekitar jalan, termasuk di persimpangan jalan, jalan layang, jembatan dan jalan di bawah tanah. (SNI 7391:2008). Kondisi penerangan jalan umum di dalam delineasi kawasan tiga desa tersebut masih belum terlengkapi. Sehingga, fasilitas penerangan jalan umum sangat diperlukan.
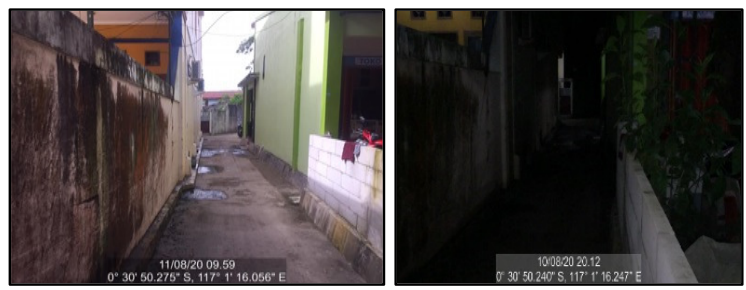

Gambar 4. Salah satu kondisi penerangan, dengan pengambilan foto pada 09.59 dan 20.12 WITA

\section{Peningkatan Kualitas Permukiman Kumuh}

Konsep peningkatan kualitas permukiman kumuh di Desa Loh Sumber melalui kegiatan peremajaan, dengan pola-pola peningkatan terhadap kualitas permukiman kumuh, adalah:

\section{Konsep Bangunan}

Peremajaan diartikan sebagai upaya dalam meningkatan kualitas melalui renovasi dan revitalisasi. Renovasi melakukan perubahan sebagian atau beberapa komponen pembentuk permukiman agar dapat beradaptasi dan menampung fungsi baru, sedangkan revitalisasi melakukan perbaikan dan mendorong ekonomi kawasan, yang meliputi penggunaan material atap bangunan, dan penggunaan jenis kayu sebagai bahan bangunan yang memiliki daya tahan kuat terhadap air. Terdapat 6 (enam) titik lokasi perbaikan untuk peremajaan bangunan di Desa Loh Sumber, yaitu:
a. Jl. Mulyo Pranoto Gang Dahlia, RT. 02,
b. Jl. Mulyo Pranoto Gang Kenanga, RT. 02.
c. Jl. Mulyo Pranoto, Gang Murai RT. 03.
d. Jl. Mulyo Pranoto Gang Nusa Indah RT. 02.
e. Jl. Mulyo Pranoto Gang Melati, RT. 02.
f. Jl. Mulyo Pranoto, Gang Anggrek, RT. 02. 
Cantilever | Volume: 10 Nomor: 01 April $2021 \mid$ ISSN: 1907-4247 (Print) $\mid$ ISSN: 2477-4863 (Online) $\mid$ Website: http://cantilever.id Lisa Astria Milasari, dkk. | Analisis Peningkatan Kualitas Permukiman Kumuh di Desa Loh Sumber Kabupaten Kutai Kartanegara

\section{Konsep Jalan dan Drainase Lingkungan}

Pengembangan infrastruktur jaringan jalan lingkungan berupa perbaikan jalan lingkungan dengan material beton dan paving block, serta pemeliharaan jalan lingkungan dengan pemasangan plang nama sebagai penanda nama jalan/nama gang pada titik lokasi tertentu.

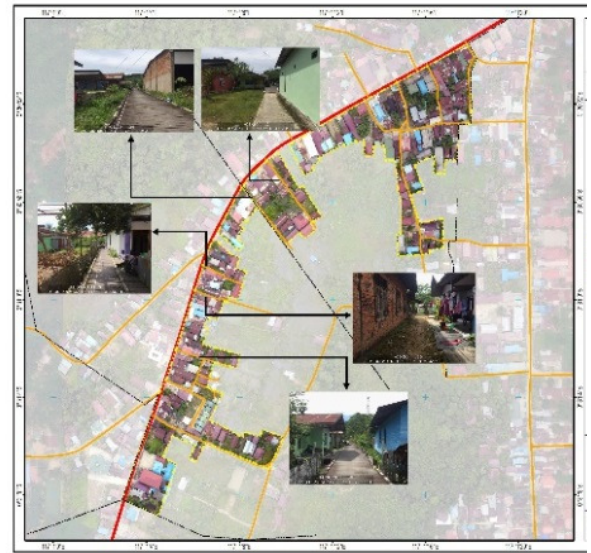

Gambar 5. Peta Rencana lokasi Kondisi Jaringan Jalan

a. Jalan Paving Block

Diaplikasikan konsep warna merah, kuning dan putih yang didasari dari lambang Kabupaten Kutai Kartanegara, yaitu: warna kuning yang melambangkan keagungan, warna merah yang melambangkan tentang keberanian, kegigihan, kejujuran dan jiwa ksatrian, dan warna putih yang melambangkan kebenaran, keikhlasan dan kesucian. Lokasi perbaikan di Desa Loh Sumber, adalah:

a. Jl. Mulyo Pranoto Gang Dahlia, RT. 02.

b. J1. Mulyo Pranoto Gang Kenanga, RT. 02.

c. Jl. Mulyo Pranoto, Gang Murai RT. 03.

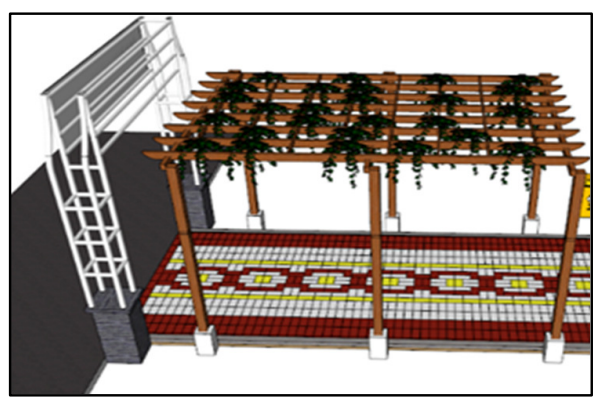

Gambar 6. Salah satu bentuk Paving block
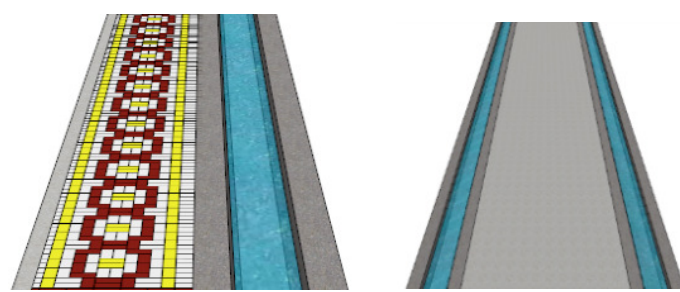

Gambar 7. Bentuk 3D Konsep Drainase lingkungan untuk jalan beton dan paving block

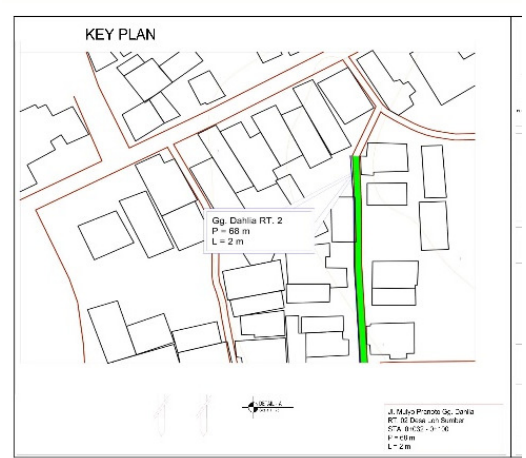

Gambar 8. Salah satu rencana konsep jalan lingkungan

b. Jalan Beton

Standar Acuan yang digunakan adalah SNI 84572017 tentang Rancangan Tebal Jalan Beton untuk Lalu Lintas Rendah, Pd T-142003 tentang Pelaksanaan Perkerasan Jalan Beton Semen, dan Manual Desain Perkerasan Jalan Bina Marga (2017). Perkerasan jalan beton tanpa tulangan terbuat dari bahan semen, pasir, dan kerikil yang ditambah air secukupnya. Perkerasan ini tidak digunakan untuk jalan lingkungan atau permukiman yang tanah dasarnya labil, mudah pecah, lembek, pedaturan/tanjalkan, dan di atas singkapan batu. Lokasi perbaikan di Desa Loh Sumber, adalah:

a. Jl. Mulyo Pranoto Gang Nusa Indah RT. 02.

b. Jl. Mulyo Pranoto Gang Melati, RT. 02.

c. Jl. Mulyo Pranoto, Gang Anggrek, RT. 02.

d. Jl. Mulyo Pranoto Gang Gunung Timur, RT. 03.

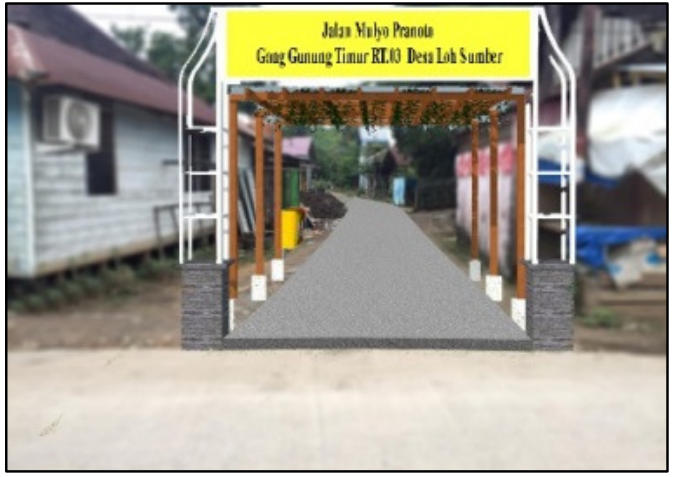

Gambar 9. Jalan beton pada Gang Gunung Timur, RT. 03

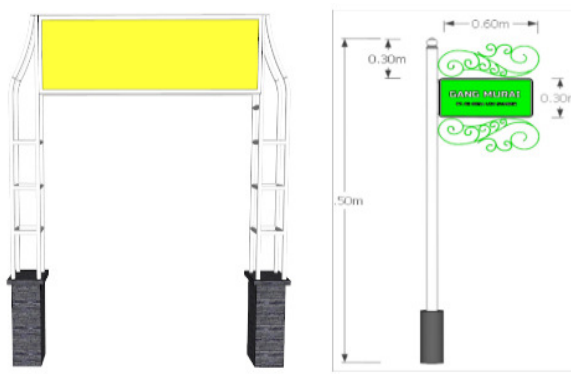

Gambar 10. Bentuk 3D papan nama 


\section{Konsep penyediaan air bersih}

Berdasarkan hasil analisis sebelumnya, kawasan permukiman di Desa Loh Sumber memerlukan sistem yang berbasis sistem individual. Sistem individual dapat dikembangkan menjadi komunal untuk beberapa unit rumah tangga pada Desa Loh Sumber dengan partisipasi masyarakat. Pemanfaatan sumber air bersih dapat dilakukan secara bersamasama s/d 12 keluarga.

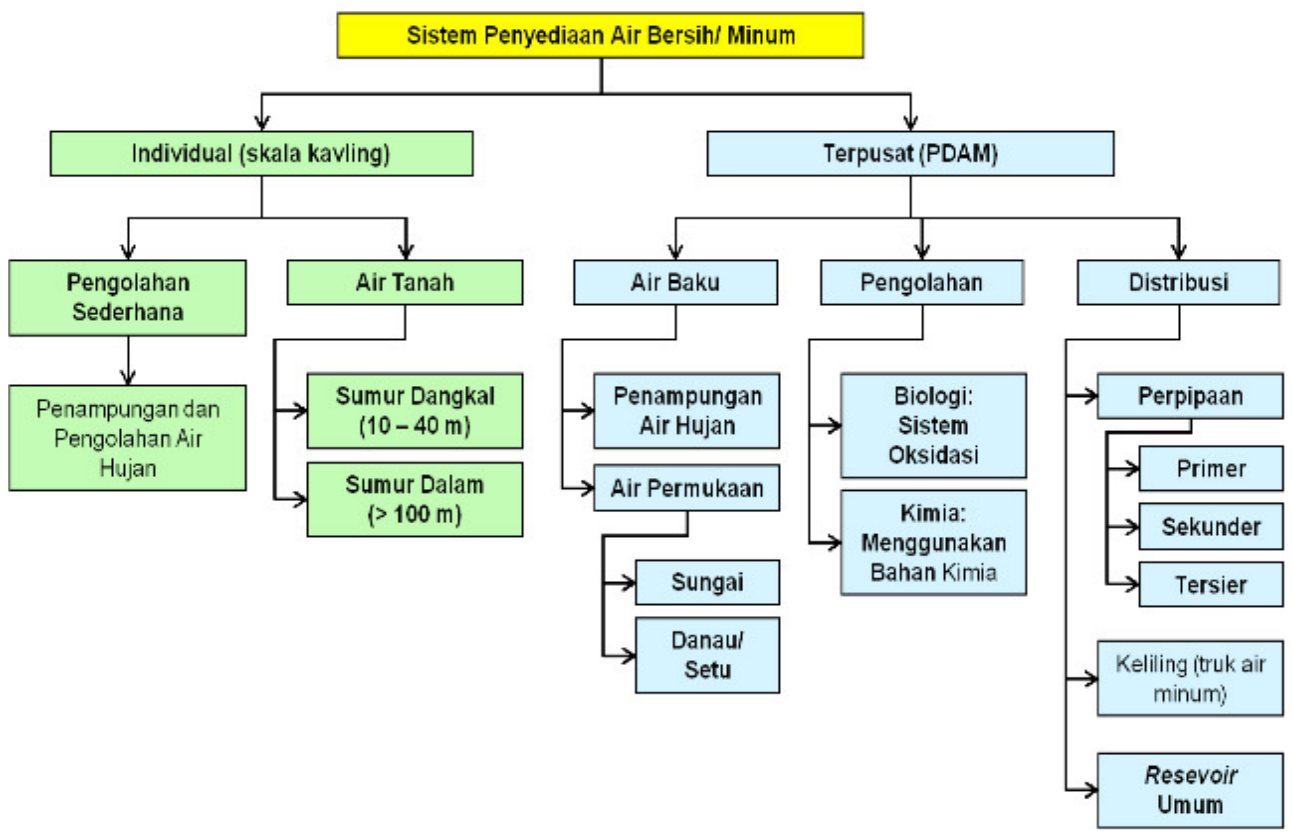

Gambar 11. Skema Penyediaan Air Bersih

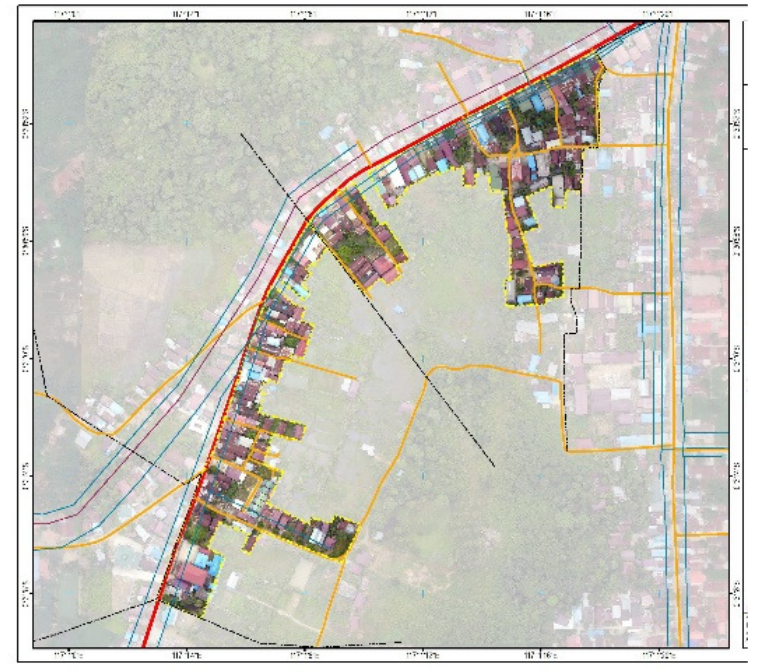

Gambar 12. Peta Rencana Air Minum

\section{Konsep Pengelolaan air limbah/sanitasi}

Pada kawasan kumuh perkotaan ini, belum tersedia fasilitas pengolahan limbah (IPAL dan IPLT), sehingga pengelolaannya belum memadai. Pengolahan individual mengakibatkan tidak terkendalinya sistem pembuangan kawasan. Dibutuhkan pengolahan air limbah komunal, sehingga air limbah dapat lebih dikendalikan dan dikontrol olah publik dan lingkungan sekitarnya.

Sesuai kondisi eksisting, skenario awal yang dapat dilakukan adalah dengan memberi bantuan fisik sistem komunal yang dilakukan oleh pemerintah yang berupa IPAL/IPLT skala permukiman. Sedangkan secara non fisik perlu dilakukan sosialisasi dan penyuluhan mengenai penentuan lokasi dan pengelolaan sanitasi, yang dapat dilakukan oleh masyarakat secara komunal.

\section{Konsep Pengelolaan Persampahan}

Pada wilayah Kecamatan Loa Kulu Kota, belum tersedia sarana dan prasarana persampahan. Secara umum, sampah di Desa Loh Sumber masih dikelola secara swadaya oleh masyarakat. Sehingga, harus dikelola terintegrasi dalam suatu lingkungan permukiman di RT. 02 dan RT. 03. Biasanya, kota memiliki dinas yang mengurusi persampahan, dan perlu dilakukan sosialisasi dan penyuluhan mengenai penentuan lokasi TPS dan pengelolaan persampahan. Pada konsep pengelolaan persampahan diperlukan rencana tempat penampungan sementara sampah 3R (TPS 3R). Skema pengelolaan sampah secara umum tersaji dalam Gambar 14. 
Cantilever | Volume: 10 Nomor: 01 April 2021 | ISSN: 1907-4247 (Print) | ISSN: 2477-4863 (Online) | Website: http://cantilever.id Lisa Astria Milasari, dkk. | Analisis Peningkatan Kualitas Permukiman Kumuh di Desa Loh Sumber Kabupaten Kutai Kartanegara
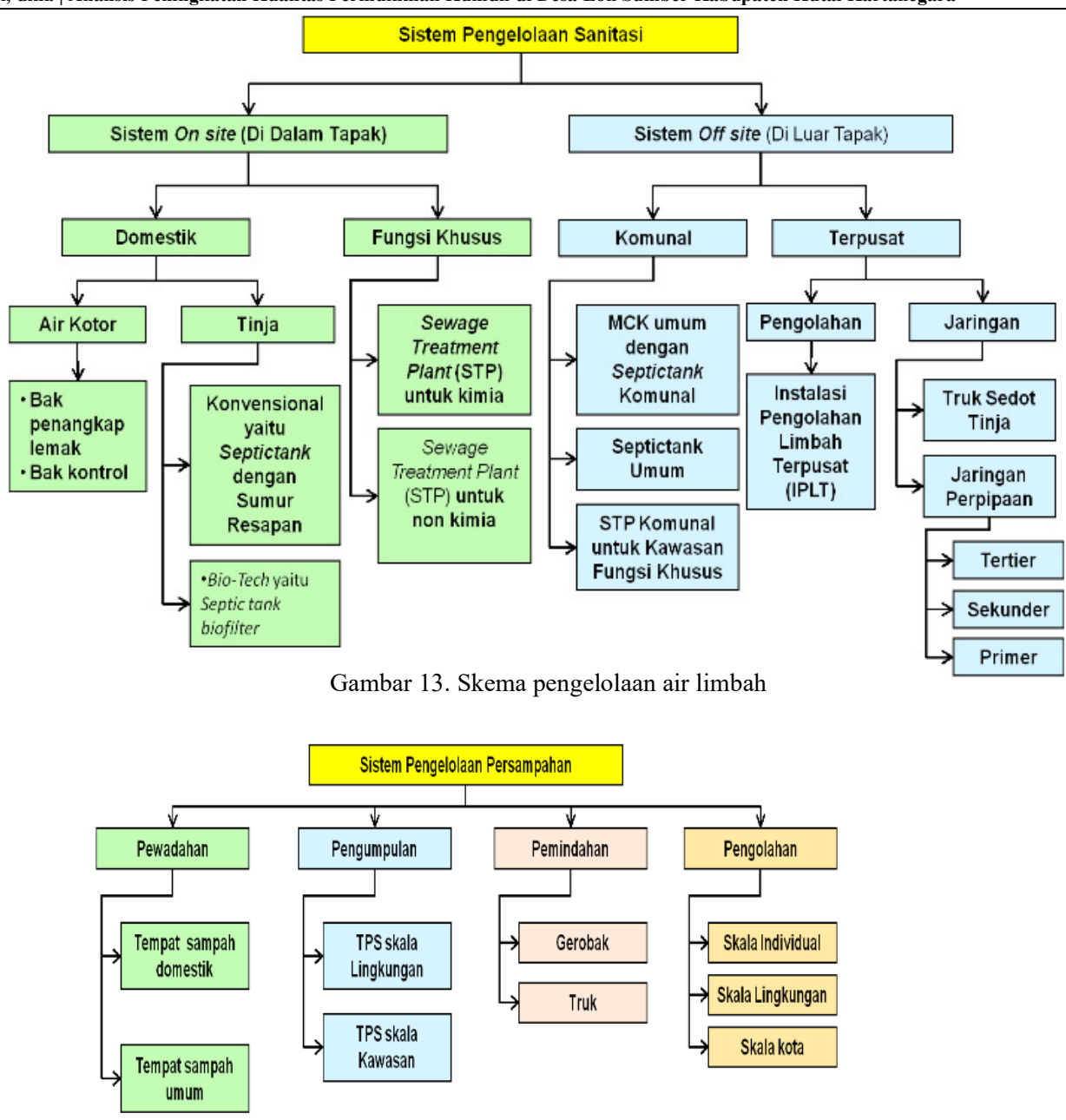

Gambar 14. Skema pengolahan persampahan

TPS komunal, dengan bantuan partisipasi masyarakat, akan dialokasikan pada RT.02. Mengacu pada (Permen PU No. 03/PRT/M/2013 tentang Penyelenggaraan Prasarana dan Sarana Persampahan dalam Penanganan Sampah Rumah Tangga dan Sampah Sejenis Samah Rumah Tangga), TPS ini digunakan untuk menampung sampah sementara sebelum sampah diangkut ke TPA.

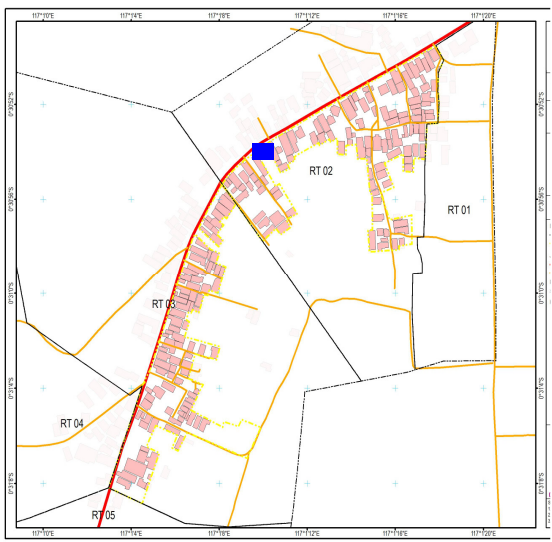

Gambar 15. Rencana Lokasi TPS di Desa Loh Sumber

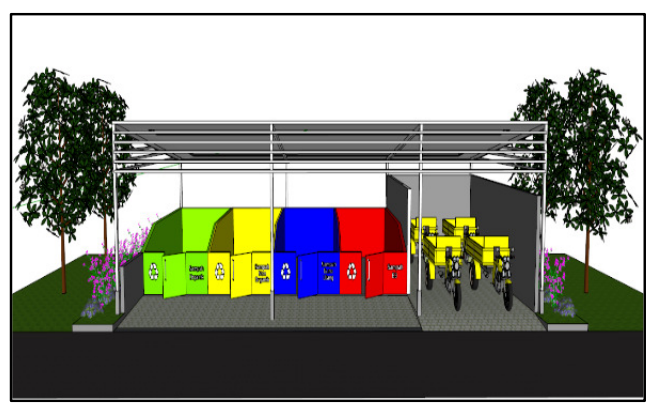

Gambar 16. Bentuk 3D TPS Desa Loh Sumber

Diharapkan adanya swadaya dalam pengelolaan sampah berbasis masyarakat, baik itu langsung menjadi produk daur ulang, maupun bekerja sama dengan pemerintah daerah.

\section{Konsep Penerangan Jalan Umum (PJU)}

Konsep penerangan jalan umum pada kawasan kumuh perkotaan di rencanakan pembangunan pada tiap titik lokasi dengan kriteria jalan lingkungan lebar minimal 1,5 meter hingga 2 meter (SNI 7391:2008 tentang Spesifikasi Penerangan Jalan di 
Kawasan Perkotaan). Adapun titik lokasinya, yaitu: Gang Dahlia, RT. 02, Gang Kenanga, RT. 02, Gang Nusa Indah RT. 02, Gang Melati, RT. 02, Gang Anggrek RT. 02, Gang Murai RT. 03, dan Gang Gunung Timur, RT. 03. Gambar 16 memperlihatkan rencana lokasi PJU, dan Gambar 17 memperlihatkan bentuk 3D konsep penerangan jalan umum yang akan diletakkan pada titik lokasi permukiman.

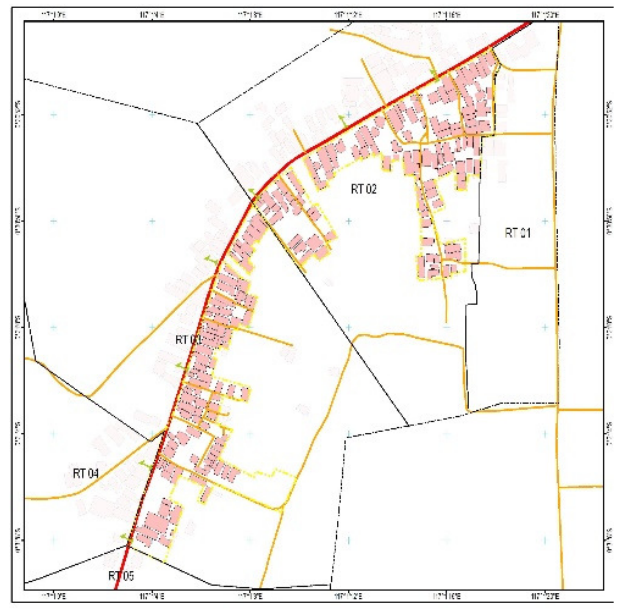

Gambar 17. Peta Rencana Lokasi PJU

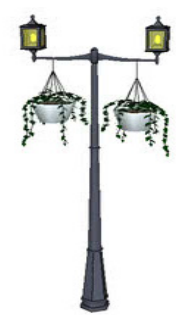

Gambar 18. Bentuk 3D Konsep Penerangan Jalan Umum

\section{KESIMPULAN}

Konsep penanganannya untuk peningkatan kualitas permukiman kumuh di Desa Loh Sumber, Kecamatan Loa Kulu Kota, Kabupaten Kutai Kartanegara, adalah:

1. Konsep bangunan dilakukan dengan peremajaan, berupa renovasi dan rehab pada enam titik lokasi, yaitu: J1. Mulyo Pranoto Gang Dahlia, RT. 02, Gang Kenanga, RT. 02, Gang Murai RT. 03, Gang Nusa Indah RT. 02, Desa Loh Sumber, Gang Melati, RT. 02, dan Gang Anggrek, RT. 02 Desa Loh Sumber.

2. Lokasi perbaikan jalan lingkungan yang berupa Gang Nusa Indah RT. 02, Gang Melati, RT. 02, Gang Anggrek, RT. 02, Gang Dahlia, RT. 02, Gang Kenanga, RT. 02, Desa Loh Sumber, Gang Murai RT. 03, Gang Gunung Timur RT. 03 Desa Loh Sumber.
3. Lokasi penataan drainase pada tiap titik yang sesuai dengan titik rencana lokasi jalan lingkungan.

4. Penyediaan air bersih menggunakan sistem individual yang dapat dikembangkan menjadi komunal untuk beberapa unit rumah tangga dengan partisipasi masyarakat.

5. Pengelolaan dan pengolahan sampah di Desa Loh Sumber masih dikelola secara swadaya masyarakat. Sehingga, harus dikelola secara terintegrasi dalam lingkungan permukiman di RT. 02 dan RT. 03.

6. Penempatan penerangan jalan umum harus dilakukan agar meminimalisir terjadinya kriminalitas. Terdapat 7 titik lokasi, yaitu: Gang Dahlia, RT. 02, Gang Kenanga, RT. 02, Gang Nusa Indah RT. 02, Gang Melati, RT. 02, Gang Anggrek RT. 02, Gang Murai RT. 03, dan Gang Gunung Timur, RT. 03.

Dari hasil penelitian ini, diperoleh arahan penanganan permukiman kumuh secara terpadu dan komprehensif melalui program-program permukiman dari segi pembangunan dan pengelolaan infrastruktur serta lingkungan.

\section{REFERENSI}

Adisasmita, R. (2005). Pembangunan Ekonomi Perkotaan. Yogyakarta: Graha Ilmu.

Budiharjo, E. (2009). Perumahan dan Permukiman di Indonesia. Bandung: PT.Alumni.

Emzir. (2012). Metodologi Penelitian Kualitatif Analisis Data. Jakarta: Rajawali Pers.

Milasari, L. A. (2020). Kajian Bentuk Dasar Permukiman Kumuh Pada Pusat Perkotaan Kabupaten Kutai Kartanegara. Kurva S, 8(1), 41-49.

Nursyahbani, R., \& Pigawati, B. (2015). Kajian Karakteritik Kawasan Permukiman Kumuh di Kampung Kota. Jurnal Teknik PWK, 4(2), 267-281.

Peraturan Bupati Kutai Kartanegara No 119 Tahun 2016 tentang Pencegahan dan Peningkatan Kualitas Perumahan Kumuh dan Permukiman Kumuh. (n.d.).

Peraturan Bupati Kutai Kartanegara Nomor 376/SKBUP/HK/2016 tentang Penetapan Lokasi Kawasan Permukiman Kumuh. (t.thn.).

Permen PU No. 03/PRT/M/2013 tentang Penyelenggaraan Prasarana dan Sarana Persampahan dalam Penanganan Sampah Rumah Tangga dan Sampah Sejenis Samah Rumah Tangga. (n.d.).

Sastra, S. M., \& Marlina, E. (2006). Perencanaan dan Pengembangan Perumahan. Yogyakarta: Penerbit Andi Yogyakarta.

SNI 7391:2008 tentang Spesifikasi Penerangan Jalan di Kawasan Perkotaan. (n.d.).

UU No 1 Tahun 2011 tentang Perumahan dan Kawasan Permukiman. (n.d.). Jakarta.

Yunus, H. S. (2000). Struktur Tata Ruang Kota. Yogyakarta: Pustaka Pelajar. 